\title{
Diminished Gastrointestinal Potentiation of Insulin Secretion in Human Pregnancy
}

\author{
P. Hornnes, C. Kühl, and J. G. Klebe \\ Department of Internal Medicine (T), Bispebjerg Hospital and Department of Obstetrics and Gynaecology, \\ Oeresundshospitalet, University of Copenhagen, Copenhagen, Denmark
}

Summary. In order to investigate whether an increased gastrointestinal potentiation of glucoseinduced insulin release might be involved in the enhanced insulin response to oral glucose in pregnancy, seven normal women were subjected to an oral glucose tolerance test (OGTT) and an IV glucose infusion test (IVGI) in the last trimester of pregnancy and again four to ten weeks post-partum. The amount of glucose administered intravenously was adjusted to obtain plasma glucose concentrations similar to those of the preceding OGTT. By this technique it was possible to quantitate the amount of insulin release attributable to gastrointestinal factors. Contrary to expectations, the results revealed that the gastrointestinal potentiation of insulin secretion was reduced by more than $75 \%$ in late pregnancy ( $p$ $<0.05$ ). The hyperinsulinaemia of pregnancy is therefore not explained by an increased activity of the entero-insular axis. Moreover the results confirm a substantially increased beta cell sensitivity to a glycaemic stimulus in pregnancy.

Key words: Insulin secretion, incretin effect, enteroinsular axis, gastro-intestinal hormones, diabetes in pregnancy, pregnancy.

It is well established that the insulin response to oral glucose ingestion is increased in normal pregnancy [1-3], but the mechanism that mediates this increased response in unknown.

Oral intake of glucose by normal subjects causes an insulin release larger than that observed after IV administration of glucose $[4,5]$. This difference has been ascribed to the potentiation of insulin secretion by factors released by glucose from the digestive tract
[6]. The nature of these factors, termed incretin [7], has, however, not yet been fully identified, although recent investigations have shown gastric inhibitory polypeptide as a likely candidate [8-10].

Pregnancy brings about many changes in gastrointestinal physiology [11] and it was conceivable that the incretin effect could also be altered. As an increased incretin effect in gestation might help explain the increased glucose-induced insulin release of these women, a study designed to estimate the effect of pregnancy on the magnitude of the incretin effect was initiated.

In order to quantitate the incretin effect it was necessary to administer glucose intravenously as well as orally, with the aim of providing an equal glycaemic stimulus by the two routes. The difference between the the insulin responses observed during the two tests should then reflect and give a measure of the incretin effect.

\section{Materials and Methods}

\section{Subjects}

Seven healthy, normal weight females aged 19 to 28 years (mean 25.0 years) were studied twice: once between the $32 \mathrm{nd}$ and 38th week of gestation and again four to ten weeks post-partum. None received diuretics or any other drug during pregnancy and prior to the actual pregnancy all were within $10 \%$ of their ideal body weight [12]. None had a family history of diabetes and none had glucosuria. The average parity was 1 (range $0-1$ ). All women gave birth to a healthy child of normal body weight (mean $3371 \mathrm{~g}$, range $2600-3800 \mathrm{~g}$ ) at term. Informed consent was obtained from all persons.

\section{Investigative Procedures}

For at least three days prior to each test day all subjects ate a normal full diet containing 2000 calories and at least $300 \mathrm{~g}$ of 
Table 1. Effect of pregnancy on basal plasma glucose and insulin levels. Values shown are mean $\pm \operatorname{SEM}(\mathrm{n}=7)$

\begin{tabular}{llll}
\hline & $\begin{array}{l}\text { Late } \\
\text { pregnancy }\end{array}$ & $\begin{array}{l}\text { Post } \\
\text { partum }\end{array}$ & $\begin{array}{l}\text { Level of } \\
\text { significance }\end{array}$ \\
\hline Glucose $(\mathrm{mmol} / \mathrm{l})$ & $4.4 \pm 0.1$ & $4.8 \pm 0.1$ & $\mathrm{p}<0.01$ \\
Insulin $(\mu \mathrm{U} / \mathrm{ml})$ & $5.3 \pm 0.4$ & $3.8 \pm 0.4$ & $\mathrm{p}<0.001$ \\
\hline
\end{tabular}

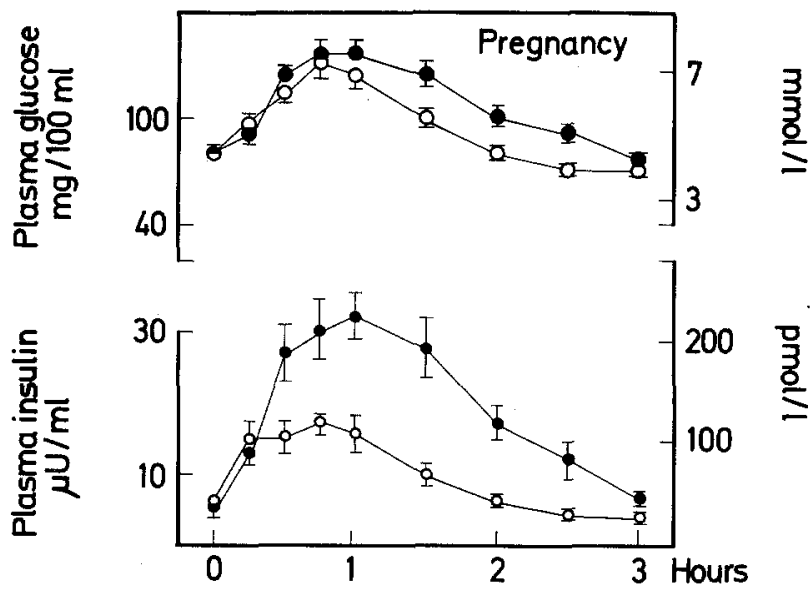

Fig. 1. Plasma glucose and insulin concentrations following oral glucose (closed circles) and IV glucose (open circles) in pregnancy. Details are described in the Methods section

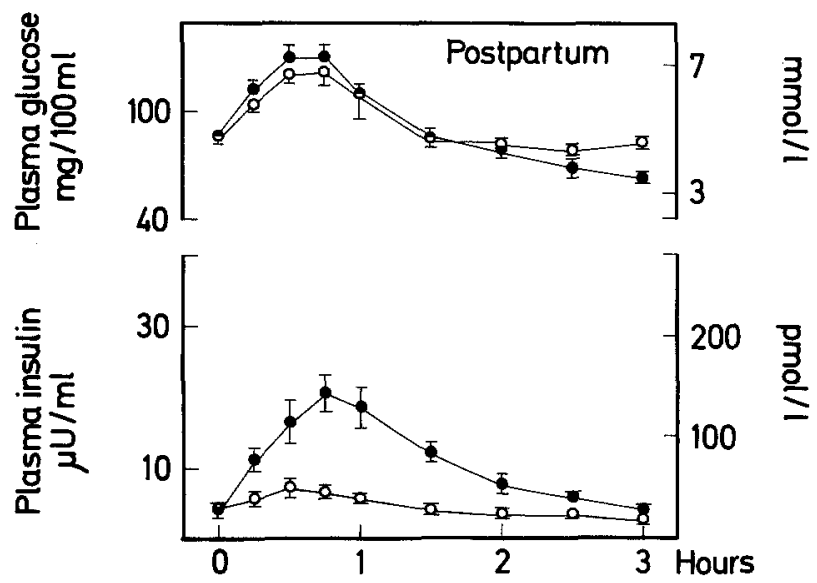

Fig. 2. Plasma glucose and insulin concentrations following oral glucose (closed circles) and IV glucose (open circles) post partum. Details are described in the Methods section

carbohydrate. The tests were performed in the morning after an overnight fast and with abstinence from smoking. Immediately upon arrival an IV cannula was inserted into an antecubital vein and $20 \mathrm{~min}$ elapsed before further investigation. On the first day an OGTT was performed giving $50 \mathrm{~g}$ of glucose in $200 \mathrm{ml}$ of water flavoured with lemon. Three to five days later an IV glucose infusion test (IVGI) designed to imitate the blood glucose course during the preceding OGTT was performed. Glucose was infused as a $50 \%$ solution into an antecubital vein by means of a variable speed pump. The rate of infusion was adjusted according to frequent blood glucose determinations by the Dextrostix-Eyetone system [13]. Blood samples were drawn ten and five minutes before the start of glucose administration and $15,30,45,60,90,120,150$, and 180 minutes after. The samples were drawn into chilled heparin tubes containing Trasylol $500 \mathrm{KIU}$ per $\mathrm{ml}$ of blood. Tubes were centrifuged at $4{ }^{\circ} \mathrm{C}$ within $30 \mathrm{~min}$ and the plasma stored at $-25^{\circ}$ until assayed.

\section{Laboratory Analyses}

Plasma was assayed for glucose on a Technicon Auto-Analyzer by a glucose oxidase method [14] and for insulin by radioimmunoassay [3]. The insulin assay has recently been modified to allow separation by means of charcoal. The detection limit of this assay was less than $0.3 \mu \mathrm{U} / \mathrm{ml}$. The within-assay coefficient of variation was $3.0 \%$ and between-assay coefficient of variation $10.0 \%$ at a level of $21 \mu \mathrm{U} / \mathrm{ml}$. All samples were assayed in triplicate.

\section{Calculations}

The net amount of glucose stimulation was calculated by integration of the glucose concentration curve and the net increase in the amount of insulin secreted was calculated by integration of the insulin concentration curve. The magnitude of the incretin effect was calculated from the formula:

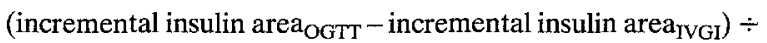
incremental insulin area ${ }_{\text {IVGI }}$.

Values were calculated for the entire $180 \mathrm{~min}$ of the tests. However, since glucose concentrations following oral and IV glucose administration differed slightly after $60 \mathrm{~min}$, values were also calculated for the first $60 \mathrm{~min}$ of the tests only. During this period glucose concentrations were practically identical following oral and IV administration both in pregnancy and post-partum. The significance of difference between means was estimated by Student's $t$-test for paired observations, and differences resulting in $\mathrm{p}$ values below 0.05 were considered significant. All values are given as mean $\pm \mathrm{SEM}$.

\section{Results}

Basal glucose levels were lower in late pregnancy than post-partum, whereas basal insulin levels were higher (Table 1). After oral glucose in late pregnancy plasma glucose concentrations reached a peak value of $7.6 \pm 0.4 \mathrm{mmol} / 1$ at $45 \mathrm{~min}$, whereas the peak value post-partum was reached at $30 \mathrm{~min}$ and averaged $7.2 \pm 0.4 \mathrm{mmol} / 1$ (Figs. 1 and 2). There was reasonable correspondence of plasma glucose concentrations during the IVGI when compared with the OGTT. In late pregnancy plasma glucose levels during the IVGI were very close to the values obtained during the preceding OGTT during the first $60 \mathrm{~min}$ of the test; thereafter they were somewhat lower (Fig. 1). Post-partum the glucose values during IVGI were very similar to those found during the OGTT for the first $120 \mathrm{~min}$ of the test; thereafter they were slightly higher (Fig. 2).

The mean amount of glucose required intravenously during the IVGI to match the blood glucose values found in the OGTT was greater in late gestation than post-partum (Table 2), but the difference was not significant.

During OGTT the insulin levels were higher in late pregnancy than post-partum, the mean concen- 
Table 2. Effect of pregnancy on the integrated glucose and insulin areas during an oral glucose tolerance test (OGTT) and an IV glucose infusion test (IVGI). Details are described in the Methods section. Areas are calculated for the periods 0-60 min and 0-180 min. Also shown is the effect of pregnancy on the incretin effect on insulin secretion calculated for same periods according to the formula:

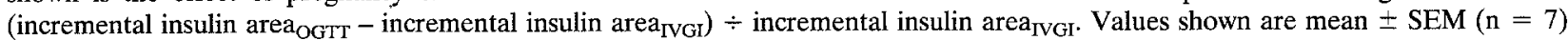

\begin{tabular}{|c|c|c|c|}
\hline & Late pregnancy & Post partum & Level of significance \\
\hline \multicolumn{4}{|l|}{$0-60$ min values } \\
\hline \multicolumn{4}{|l|}{ Incremental glucose ạrea } \\
\hline during OGTT $((\mathrm{mmol} / \mathrm{l}) \times \mathrm{min})$ & $107 \pm 22$ & $83 \pm 24$ & N.S. \\
\hline \multicolumn{4}{|l|}{ Incremental glucose area } \\
\hline during IVGI $((\mathrm{mmol} / \mathrm{l}) \times \mathrm{min})$ & $99 \pm 26$ & $69 \pm 19$ & N.S. \\
\hline \multicolumn{4}{|l|}{ Incremental insulin area } \\
\hline during OGTT $((\mu \mathrm{U} / \mathrm{ml}) \times \min )$ & $1082 \pm 80$ & $723 \pm 134$ & $\mathrm{p}<0.05$ \\
\hline \multicolumn{4}{|l|}{ Incremental insulin area } \\
\hline during IVGI $((\mu \mathrm{U} / \mathrm{ml}) \times \min )$ & $560 \pm 88$ & $144 \pm 21$ & $\mathrm{p}<0.001$ \\
\hline Incretin effect & $1.0 \pm \quad 0.3$ & $4.5 \pm 1.0$ & $\mathrm{p}<0.05$ \\
\hline \multicolumn{4}{|l|}{$0-180 \mathrm{~min}$ values } \\
\hline \multicolumn{4}{|l|}{ Incremental glucose area } \\
\hline \multicolumn{4}{|l|}{ Incremental glucose area } \\
\hline during IVGI $((\mathrm{mmol} / \mathrm{l}) \times \mathrm{min})$ & $185 \pm 49$ & $147 \pm 44$ & N.S. \\
\hline \multicolumn{4}{|l|}{ Incremental insulin area } \\
\hline during OGTT $((\mu \mathrm{U} / \mathrm{ml}) \times \min )$ & $2693 \pm 190$ & $1522 \pm 140$ & $\mathrm{p}<0.005$ \\
\hline \multicolumn{4}{|l|}{ Incremental insulin area } \\
\hline during IVGI $((\mu \mathrm{U} / \mathrm{ml}) \times \min )$ & $1072 \pm 383$ & $282 \pm 54$ & $\mathrm{p}<0.005$ \\
\hline Incretin effect & $1.7 \pm 0.4$ & $4.9 \pm \quad 1.2$ & $\mathrm{p}<0.05$ \\
\hline \multicolumn{4}{|l|}{ Amount of glucose infused } \\
\hline (g) & $16.3 \pm 2.1$ & $12.0 \pm \quad 3.1$ & N.S. \\
\hline
\end{tabular}

N. S. denotes no significance

trations from 30 through $180 \mathrm{~min}$ all being significantly enhanced. Also the mean incremental insulin areas calculated for the first $60 \mathrm{~min}$ and the entire $180 \mathrm{~min}$ of the tests were higher in late pregnancy than post-partum (Table 2). During the IVGI the insulin levels were higher in late pregnancy than post-partum, resulting in increased mean incremental insulin areas (Table 2).

The results obtained allowed the calculation of the incretin effect which was found to be reduced by two thirds in late pregnancy (Table 2).

Comparison of the glucose concentrations obtained during the entire IVGI in pregnancy and post-partum showed that the mean concentrations were slightly lower in late pregnancy than post-partum for the first $15 \mathrm{~min}$ of the test; thereafter there were no significant differences until $150 \mathrm{~min}$. Thus during the IVGI the glycaemic stimulus to the endocrine pancreas was almost identical during gestation and after delivery. In contrast, the mean insulin responses differed significantly, the response of late pregnancy being more than five times larger than that observed post-partum (Table 2).

\section{Discussion}

When glucose is given orally the beta cell is stimulated by non-glycaemic as well as by glycaemic stimuli. In the present investigation we have at- tempted to determine how much of the total insulin secretion can be attributed to each of the two stimuli. When insulin secretion was induced by IV glucose alone it was found that this part of the total stimulation could account for half of the insulin response to oral glucose in pregnancy but only one fifth of the insulin response post partum. It thus seems that less of the insulin response to oral glucose in pregnancy is due to the non-glycemic fraction of the stimulus than observed post partum. This finding indicates that the incretin effect is proportionately reduced in late pregnancy.

The incretin effect has previously been estimated in pregnant Natal Indians in an investigation comparing diabetics belonging to White's group A [15] and normal pregnant Natal Indians [16]. The incretin effect was found to be decreased in the pregnant diabetics, but comparison with post-partum findings were not done. For this reason and because of the special carbohydrate metabolism of Natal Indians [16] and because of technical differences between the investigations the results cannot be directly compared with ours.

The finding of decreased basal glucose levels and increased basal insulin levels in pregnancy are in accord with previous findings $[1-3,5]$, as is the finding of an increased insulin response to oral glucose in pregnancy [1].

The insulin response to IV glucose in pregnant women has been investigated previously $[17,18]$ but 
not during a simulation of the physiological oral glycaemic stimulation. Our results permit this comparison to be made as the glucose curves during the IVGIs were practically identical during pregnancy and post-partum (Figs. 1 and 2). We found a highly significant five-fold increase in beta cell sensitivity to an IV glycaemic stimulation in late pregnancy (Table 2).

The reason for the diabetogenicity of pregnancy has still not been elucidated [19]. The decreased glucose tolerance in spite of increased insulin release seems to indicate a peripheral resistance to insulin in pregnancy for which the increased sensitivity of the beta cell to glycaemic stimulation might be a compensating measure. However, this compensation is not sufficient for glucose tolerance does deteriorate in pregnancy. However, it is possible that an unimpaired incretin effect might have brought about enough insulin release to overcome the decreased glucose tolerance.

Intensive investigations have been carried out in order to identify the factor(s) responsible for the incretin effect $[20,21]$. As there is no evidence of the effect being mediated by a neural influence on the endocrine pancreas [22] it is conceived as being of hormonal nature. The gastrointestinal hormone or hormones implicated have, however, not yet been fully identified even though recent studies seem to indicate that gastric inhibitory polypeptide is a likely candidate [8-10].

It has shown that the incretin effect remains unaffected after removal of even very large amounts of the digestive tract $[23,24]$. This indicates that even a minor, and almost any, part of the digestive tract is able to fulfil the incretin function. The reduction of the incretin effect by approximately $75 \%$ in normal late pregnancy therefore implies that the gestational modification of this gastrointestinal endocrinological function is comprehensive and widely extended.

Acknowledgements. The authors are indepted to Mrs. Connie Breiner for skilled technical assistance.

This study was supported by grants from the Danish Medical Research Council (jr. no. 512-5738 and no. 512-7217) and the Danish Hospital Foundation for Medical Research. Region of Copenhagen, the Faroe Islands and Greenland (jr. no. 75/76, 27).

\section{References}

1. Bleicher, S. J., O'Sullivan, J. B., Freinkel, N.: Carbohydrate metabolism in pregnancy. $\mathrm{V}$. The interrelations of glucose, insulin and free fatty acids in late pregnancy and post partum. N. Engl. J. Med. 271, 866-872 (1964)

2. Kalkhoff, R., Schalch, D.S., Walker, J. L., Beck, P., Kipnis, D. M., Daughaday, W. H.: Diabetogenic factors associated with pregnancy. Trans. Assoc. Am. Physicians 77, 270-279 (1964)

3. Kühl, C.: Glucose metabolism during and after pregnancy in normal and gestational diabetic women. I. Influence of normal pregnancy on serum glucose and insulin concentration during basal fasting condition and after a challenge with glucose. Acta Endocrinol. (Kbh.) 79, 709-719 (1975)
4. Elrick, H., Stimmler, L., Hlad, Jr., C. J., Arai, Y.: Plasma insulin response to oral and intravenous glucose administration. $\mathbf{J}$. Clin. Endoctinol. Metab. 24, 1076-1082 (1964)

5. McIntyre, N., Holdsworth, C. D., Turner, D. S.: Intestinal factors in the control of insulin secretion. J. Clin. Endocrinol. Metab. 25, 1317-1324 (1965)

6. Perley, M. J., Kipnis, D. M.: Plasma insulin responses to oral and intravenous glucose: Studies in normal and diabetic subjects. J. Clin. Invest. 46, 1954-1962 (1967)

7. Zunz, E., LaBarre, J.: Hyperinsulinémie consécutive aprés l'injection de solution sécrétine non hypotensive. C. R. Soc. Biol. (Paris) 98, 1435-1438 (1928)

8. Pederson, R. A., Schubert, H. E., Brown, J. C.: Gastric inhibitory polypeptide. Its physiological release and insulinotropic action in the dog. Diabetes 24, 1050-1056 (1975)

9. Schauder, P., Brown, J. C., Frerichs, H., Creutzfeldt, W.: Gastric inhibitory polypeptide: effect on glucose-induced insulin release from the isolated rat pancreatic islets in vitro. Diabetologia 11, 483-484 (1975)

10. Pederson, R. A., Brown, J. C.: The insulinotropic action of gastric inhibitory polypeptide in the perfused isolated rat pancreas. Endocrinology 99, 780-785 (1976)

11. Hytten, F. E., Lind, T.: Diagnostic indices in pregnancy. Basel: Documenta Geigy 1973

12. Natvig, N.: Nye hoydevekttabeller for norske kvinner og menn. Oslo: Landsforeningen til kosthold og helse 1956

13. Scherstén, B., Kühl, C., Hollender, A., Ekman, R.: Blood glucose measurement with Dextrostix and a new reflectance meter. Br. Med. J. 1974 III, 384-387

14. Trinder, P.: Determination of glucose in blood using glucose oxidase with an alternative oxygen acceptor. Ann. Clin. Biochem. 6, 24-27 (1969)

15. White, P.: Pregnancy and diabetes. Medical aspects. Med. Clin. North Am. 49, 1015-1024 (1965)

16. Notelovitz, M., James, S.: Plasma insulin response following oral and intravenous glucose in pregnant diabetic women. Obstet. Gynecol. 48, 268-273 (1976)

17. Picard, C., Ooms, H. A., Balasee, E., Conard, V.: Effect of normal pregnancy on glucose assimilation, insulin, and nonesterified fatty acid levels. Diabetologia 4, 16-19 (1968)

18. Spellacy, W.N., Goetz, F.C., Greenberg, B. Z., Ells, J.: Plasma insulin in normal early pregnancy. Obstet. Gynecol. 25, 862-865 (1965)

19. Kühl, C.: Serum insulin and plasma glucagon in human pregnancy - on the pathogenesis of gestational diabetes. Acta Diabetol. Lat. 14, 1-8 (1977)

20. Unger, R. H., Eisentraut, A. M.: Entero-insular axis. Arch. Intern. Med. 123, 261-266 (1969)

21. Dupre, J., Curtis, J. D., Unger, R. H., Waddell, R. W., Beck, J. C.: Effects of secretin, pancreozymin, or gastrin on the response of the endocrine pancreas to administration of glucose or arginine in man. J. Clin. Invest. 48, 745-757 (1969)

22. Lindkær Jensen, S., Nielsen, O. Vagn, Kühl, C.: The enteral insulin-stimulation after pancreas transplantation in the pig. Diabetologia 12, 617-620 (1976)

23. Rehfeld, J. F., Juhl, E., Quaade, F.: Effect of jejuno-ileostomy on glucose and insulin metabolism in ten obese patients. Metabolism 19, 529-538 (1970)

24. Rehfeld, J.F., Stadil, F., Baden, H., Fishermann, K.: The enteral insulin-stimulation after Whipple's operation. Diabetologia 11, 207-210 (1975)

Received: December 6, 1977,

and in revised form: May 4, 1978

C. Kühl, M. D.

Department of Internal Medicine (Y)

Bispebjerg Hospital

23, Bispebjerg Bakke

DK-2400 Copenhagen NV

Denmark 